\title{
The Scenario of Supply Chain Management in Kuwait Food Industry
}

\author{
Abdullah E. M. F. Alrashidi, Muataz Hazza Faizi al Hazza and Ahsan Ali Khan
}

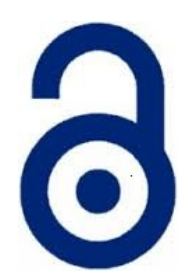

Received: 29 August 2018

Accepted: 10 September 2018

Published: 15 September 2018

Publisher: Deer Hill Publications

(c) 2018 The Author(s)

Creative Commons: CC BY 4.0

\begin{abstract}
Supply chain management (SCM) has been well known to influence the company performance in food manufacturing industries. However, the implication of SCM depends on type and culture of the companies. This paper presents the scenario of SCM in Kuwait food industry. In this study quality, time, information, flexibility, and integration have been selected as variables to predict their influence on Kuwait food industries. The methodology of the study was developed where five hypotheses have been proposed on the relationship among the selected factors and the performance. To evaluate the hypotheses, an examination through a questionnaire was conducted, followed by data analysis using Statistical Package (SPSS) and Minitab applications. It was found that out of five proposed hypothesis only two of them were supported by the analytical results. The accepted two hypothesis are related to the quality of supply chain and time management in supply chain to positively effect on the performance of food manufacturing companies. Oher three hypotheses were rejected. Information network, company flexibility and integration among the supply chain components were found to have no significant influence on the performance of food manufacturing industries in Kuwait. This study ranked the factors to prioritize to improve the performance.
\end{abstract}

Keywords: Supply chain management, Kuwaiti food industry, Quality, Balanced score card, Performance prism

\section{INTRODUCTION}

One of the performance effects commonly known in many organizations is supply chain management (SCM). It can be defined as the administrative aspect of an interconnected businesses network dealing in the product ultimate provision and service packages needed by the end customers. SCM spans all manufacturing activities and raw materials storage, inventory of the process, and finished items from the point-of-origin to the point-of-consumption. The purpose of this study is to investigate how different factors in SCM affect the food manufacturing companies' performance as well as to introduce a framework for performance improvement. This is supported with a survey among managers in different food industries to find out the relationship between these factors and food manufacturing companies' performance along with using Statistical Package for the Social Sciences (SPSS) and Minitab software to find out the most crucial factor that affects the performance food manufacturing company.

The theory on organizational extension gave the birth to the initiating idea of SCM philosophy [1]. The Hobbs' postulate was validated in a marketing framework, urged to extend the organization and all its distribution channel members near to the Porter's value system concept [2]. The tremendous technological advancement and the globalization of business have required companies to expand beyond cost and to prominence quality, speed, flexibility and agility. Competitive advantage for many manufacturers now rests upon their ability to monitor ongoing product, process innovation, and superior manufacturing. It also depends on the continuous development of current products as well as developing a continuous line of new service quality concept [3]. However, nowadays, companies are struggling to enhance their performances in all aspects specially to increase the quality at reduced cost. Improving the SCM is one of the ways to solve the issue. Thus, in this study, SCM and its consequence on food manufacturing companies' performances will be studied. As such, this research set the following objectives.

A. E.M.F. Alrashidi ${ }^{1} \otimes$, M. H. A. F. Hazza² and A. A. Khan ${ }^{3}$

Department of Manufacturing and Materials Engineering

International Islamic University Malaysia

PO Box 10, 50728 Kuala Lumpur, Malaysia

1E-mail: eng-alrashidi@live.com

2E-mail: muataz@iium.edu.my

3E-mail: aakhan@iium.edu.my 
1. To study the factors in supply chain management that are influencing the food manufacturing companies' performance.

2. To determine the importance of different factors of the supply chain management and to identify the most affecting factors on the company performance.

3. To establish the connection between the independent factors and the dependent factor as well as the relationship between the independent factors themselves.

\subsection{Research Questions}

This research is to find the relationship between the critical factors and the company's performance by focusing the major issues in SCM. The main question of this research is how the SCM can contribute to get a better result and increase an organization's productivity. The research will investigate on the factors such as quality, information, flexibility; integration and time achieve high performance in Kuwait food manufacturing companies. The research questions are as follows:

1. What are the SCM important and critical factors that influence the performance of the companies in the food manufacturing industries?

2. What are the actions to manage these factors to attain the desired improvement in an organization?

3. What type of model will be applicable to measure the performance within an organization?

4. How far the research participants know about supply chain management and its related knowledge for procurement, manufacturing, and technologies?

\subsection{Statement of Hypotheses}

Five variables affecting the food manufacturing companies' performance in the supply chain have been chosen. The selection process involved a review study and an extensive research on the SCM and performance measurement systems. The selected factors and variables are time, quality, information, integration and flexibility. The hypotheses were generated according to each of the variable:

$\mathrm{H1}$ : The higher the quality in each part of supply chain, the higher the performance of food manufacturing companies

$\mathrm{H} 2$ : Time management in supply chain has a positive impact on the performance of food manufacturing companies.

H3: The better the information network among the supply chain, the higher the influence on the performance of the food manufacturing companies.

H4: The company's flexibility to the changes of business environment has a high impact on performance.

H5: The integration among all components of supply chain has a great impact on the performance of food manufacturing companies.

\subsection{Conceptual Framework}

A few studies have been reported in the performance of food manufacturing companies. The selection of the variables involved different item from the one listed in the hypotheses, and comparisons were made to measure the performances. The current work is not identical nor similar to those has that been performed. Instead, it can be said as a complementer and contrast the other previous studies. The study aims to apply variables that are often suggested by other authors and appear to affect the performance of food manufacturing companies of the entire supply chain. As presented a classification in the literature, which involved flexibility, quality, cost and time [4]. It is a practical and convenient tool for analysing a system in an organization. The focal point of the investigation was the impact of information structure towards a supply chain performance [4]. As a complementary of the study by Zhao and Zhang [5] studied the effect of the data sharing towards the same performance.

The current work selected five factors to be assessed in terms of their performance in the supply chain. Additionally, to investigate the selected variables relation towards the performance of the companies, a conceptual framework is also introduced in this work. Inclusive for the variables in this work are time, quality, flexibility, integration and information. The dependent variable is the performance of food manufacturing companies. The authors suggest the following framework to investigate the relationship between the variables and the effect of these factors on food manufacturing companies' performance.

\section{SUPPLY CHAIN OPERATION REFERENCE}

The development on Supply Chain Operation Reference (SCOR) has been provided by the Supply Chain Council (SCC); an independent and a non-profit organization are used in combination with the attributes of performance in this model. These attributes are features of supply chain, which permit the analysis and the evaluation in contrast to other supply chains. The leading role of SCOR is the description of measurement and the assessment of the settings of supply chain. According to SCC, SCOR should be a progression reference model, which gives an interactive language in the communication between supply-chain partners. The postulation of the model was developed on four stages. These stages were the basis in drawing and defining a guide to accomplish the hypotheses of the study. It is therefore concluded that the focus of SCOR is the integration of all supply chain components and associated parties, from suppliers to suppliers, suppliers to costumers, or customers to customers. In terms of performance, the model 
also enumerates the influencing effects of quality and information towards the system. Figure 1 is an illustration of the factors that influence the performance based on the SCOR model.

\section{RESEARCH METHODOLOGY}

Data sampling concerns the process of estimating the characteristics of the whole population from the selected subset of individuals inside a population. In this research, managers from various food industries in KUWAIT are the respondents. The selected ones were those who have a good knowledge in the concept of supply chain management (SCM) and should be familiar with the position of workers in different levels of the company. It can involve also workers as long as they are aware of SCM and its relationship with the industrial engineering. The performance quantification from the food manufacturing companies was measured through a system built out of a five-metrics set. Each of the metric component was selected according to the previous studies and literature review performed by other researchers and investigators on the focused topic [6,7]. The relevancy and reliability of the composed hypotheses was tested. The evaluation employed the distribution of the questionnaire survey among managers and executive of diverse-positions, as well as its analysis with statistical tools of SPSS and MINITAB to assist the decision making process. The process of this research methodology is presented in Figure 2.

\subsection{Method and Instruments}

SPSS is a robust and responsive application for decision-making process. It has been utilized by many experts for analysing both qualitative and quantitative aspects of a decision [8]. The application has the widest services in social science that serves the function of statistical analysis. Many parties, including governments, market researchers, education researchers, health researchers, survey companies, marketing companies, and many others, benefit from the utilization of this software. The fundamental features of the application include a data documentation feature, where the data file store the metadata dictionary, and a data management feature, where the creation of data derivation, its case selection, and file reshaping occurs. The two are counted as an addition to the basic feature of the statistical analysis. The application itself is deemed as one of the most exploited methods when it comes to a decisionmaking process with several criteria and sub-criteria, through selective alteration and prioritization processes. The questionnaire includes an array of questions to be sent to the respondents, in an expectation for a response, which is sent by the investigator or researcher to the targeted peers. Most questionnaires are self-administered, in that it is distributed to the targeted respondents, asking them to complete it, and resending it back to the owner of the questionnaire $[9,10]$. An interview, at the other side, can be considered as an alternative form of a questionnaire, where the series of questions are addressed personally to the respondents [8]. Combining semi-structured interviews and structured questionnaires have been routinely performed to attain confirmatory results, regardless the differences in the methods of information collection, analysis, and data interpretation.

A comparative study on nineteen questionnaire-interviews even concluded that the statistics on their consistency and consensus between their methods were insufficient. The alignment issue of the processed data generated from the two different methods were described in the evaluation of a questionnaire-interview study of teacher apprehension.

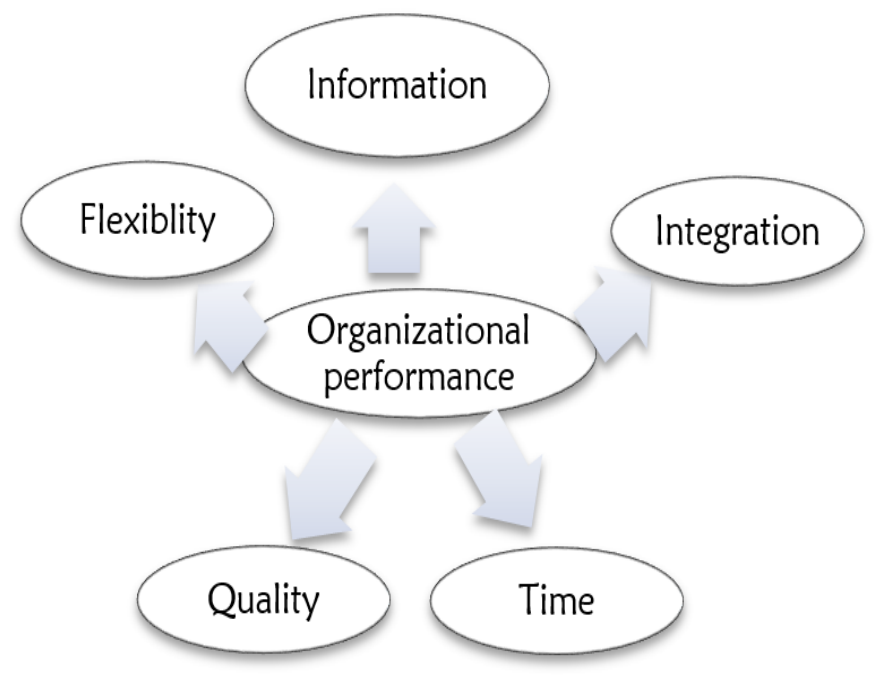

Figure 1: Conceptual framework 


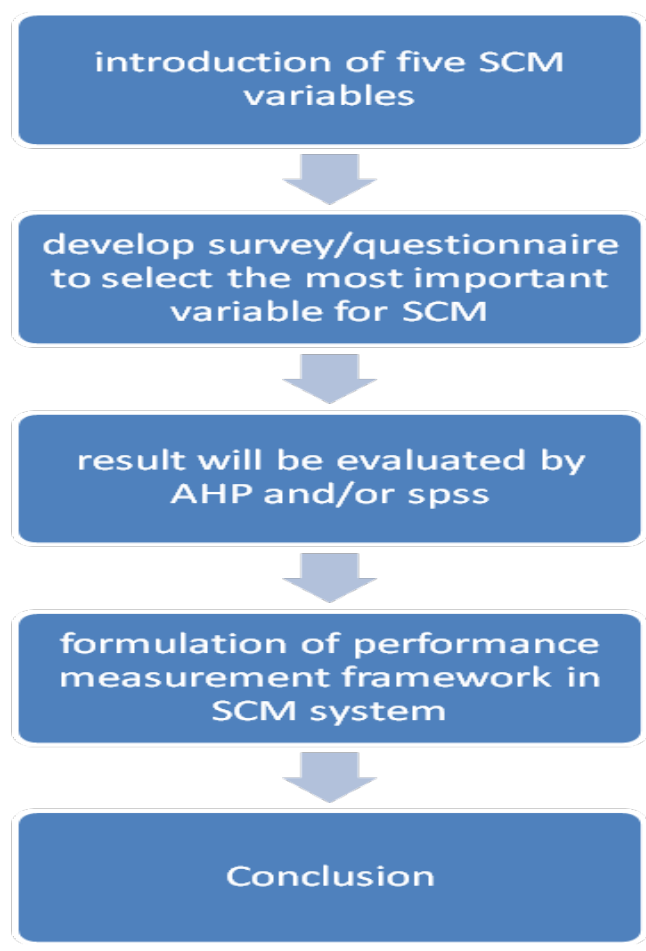

Figure 2: Research Methodology

The explanation for the poor alignment can be associated to the discrepancy in the data collection procedures. The unreliability and ramification of the investigated construct, the adversity in data correlation and comparison, possible confusion and misinterpretation from some questionnaire cues, paramount sensitiveness to context, as well as preeminent control of content exposure are also possible reasons of discrepancy. The investigators incorporates a detailed, straightforward, and highly contextualised presentation for the construct made; collecting diversified types of data in a minimum time constraint; and estimating the agreement between methods using consistency statistics. However, the substantial alignment could possibly direct the process to the loss of capacious complementary data as its confirmation cost by allowing each method to be analysed in its respective right. In the educational environment, the utilization of the combined questionnaire-interviews has found to be common [10,11]. Although questionnaires are capable of providing patterns confirmation within a large population, a qualitative interview data often bring together some better insights on the actions, attitudes, and thoughts of the respondents [12].

\subsection{Data Collection and Analysis}

Starting from $15^{\text {th }}$ June 2011 the data collection process was carried for the next two months. In the early date, the targeted companies should have received the questionnaires designated for them. Consecutively, the targeted respondents were given the ample time to fill up the information requested in the questionnaire. A $90 \%$ of the distributed questionnaire was received. The quantity of the questionnaires collected was 60 out of 67 questionnaires. The analytical stage of the study involved the empirical and descriptive methods of research analysis. Translation of the returned data with a numerical scale was performed and then SPSS analyse was conducted. The formulation of the performance measurement system involved the stages to evaluate the efficiency and productivity of the area is most relevant to the engineers in the manufacturing process.

\section{RESULTS AND DATA ANALYSIS}

The findings of the study are presented in this chapter. The analytical data of respondent as well as the feedback collected from the survey were discussed and analysed in the next sections and subsections. Correspondingly, the results were discussed by using SPSS software analysis to process the data. The results were then compared with the hypotheses proposed in this research and new suggestions were then demonstrated based on the optimum findings of the study.

\subsection{RESULTS}

The questionnaire of the survey was intended to draw the connection between food manufacturing companies' performance and quality, time, information, flexibility and integration as well as how these parameters influence each other in supply chain and how they could be managed to obtain better performance in an organization. 
Questionnaire was divided into two parts. Firstly, it includes questions about demographic data of respondents as well as to what extent respondents are familiar with supply chain management, new SCM technologies and organizational structure. Data summary is presented as qualitative analysis. The analytical data of the respondents about gender, education, age, profession as well as knowledge in SCM and its technologies are presented in Table 1. Most of the 48 respondents were male. The age of respondents was between 26 to 46 years. The result showed the respondents were mostly educated as the majority obtained bachelor or master's degrees. Nearly $50 \%$ of the respondents are employees in corporations with 100-500 members. The results of the survey would be preferable if most of the respondents were in corporations with larger number of workforces. A percentage of 70 of respondents claimed an average or high knowledge about management of supply chain, which showed satisfactory percentage for conducting the survey. A value of $9 \%$ of the respondents was aware of SCM technologies, which indicates that the SCM technologies are not well known in their companies. Secondly, comprises of questions that concern about the connection between independent and dependent variables to examine the research hypotheses. The questions related to each independent variable are grouped together. Respondents demonstrate extent of their agreement or disagreement with the research propositions by answering the questions of part $B$. The result obtained after analysing these data are provided as quantitative analysis.

\subsection{DATA ANALYSIS}

The SPSS and Minitab software were applied as tools to analyse the data by means of multiple regression method and factor analysis method after the examination the reliability and normality of the data. Normality is the first phase of screening of the data, where the data characteristics are being explored. Normality of assumption is a precondition for many inferential statistical methods. There are several ways to discover the assumption, such as leaf plot, histogram, box plot and stern. For resting the normality, factors related to each variable are grouped together and analysed.

\subsubsection{Multiple Regressions}

The term is used to acquire about the relationship between several predictor or independent variable and a criterion or dependent variable, which is fitted for this research. The multiple regressions results are calculated based an equation, which expressed the relationship between factors influencing an independent variable [13]:

$$
Y=a+B_{1} X_{1}+B_{2} X_{2+\cdots+} B_{n} X_{n}
$$

Table 1: Demographic distribution of respondents

\begin{tabular}{|c|c|c|c|c|c|}
\hline & Category & Frequency & Percent & Valid Percent & $\begin{array}{l}\text { Cumulative } \\
\text { Percent }\end{array}$ \\
\hline Gender & Male & 48 & 100.0 & 100.0 & 100.0 \\
\hline \multirow{5}{*}{ 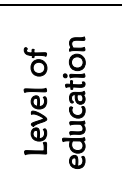 } & Diploma & 11 & 22.9 & 22.9 & 22.9 \\
\hline & Bachelor's degree & 24 & 50.0 & 50.0 & 72.9 \\
\hline & post degree & 5 & 10.4 & 10.4 & 83.3 \\
\hline & Other & 8 & 16.7 & 16.7 & 100.0 \\
\hline & Total & 48 & 100.0 & 100.0 & \\
\hline \multirow{8}{*}{ 岁 } & 30 or below & 4 & 8.3 & 8.3 & 8.3 \\
\hline & $31-35$ & 5 & 10.4 & 10.4 & 18.8 \\
\hline & $36-40$ & 11 & 22.9 & 22.9 & 41.7 \\
\hline & $41-40$ & 8 & 16.7 & 16.7 & 58.3 \\
\hline & $46-50$ & 9 & 18.8 & 18.8 & 77.1 \\
\hline & $51-55$ & 7 & 14.6 & 14.6 & 91.7 \\
\hline & above 55 & 4 & 8.3 & 8.3 & 100.0 \\
\hline & Total & 48 & 100.0 & 100.0 & \\
\hline \multirow{4}{*}{ 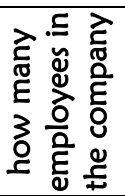 } & below 100 employees & 5 & 10.4 & 10.4 & 10.4 \\
\hline & 100-500 employees & 37 & 77.1 & 77.1 & 87.5 \\
\hline & $\begin{array}{c}\text { more than } 500 \\
\text { employees }\end{array}$ & 6 & 12.5 & 12.5 & 100.0 \\
\hline & Total & 48 & 100.0 & 100.0 & 100.0 \\
\hline
\end{tabular}

Where $B_{n}$ is the regression coefficient, expressing the amount of the dependent variable, $(Y$ varies when varying the corresponding independent factor. The value $a$ is the constant, where the regression line intercepts the $Y$-axis; represents the amount the dependent $Y$ when all the independent variables are zero. The standardized version of the $b$ coefficients is the $B$ weights, and the ratio of the $B$ variables. Associated multiple regression is $R$, multiple correlation, which is the percent of variance in the dependent variable explained collectively by all the independent 
variables. In order to run the regression test, factors related to each variable are grouped together and analysed versus independent variable namely food manufacturing companies' performance $[14,15]$ :

1. The multiple correlation coefficient is $R$ : a relation between performance and quality. The value of $R=0.494$, is acceptable but not preferable since it is not regulated to an extreme side.

2. $R$ squared value expressed the variability in loyalty is regarded by the independent variable. The value of $R$ squared $=0.244$ is slightly small and demonstrates the predictors are not considering the performance strongly.

3. Based on the findings above, the model of regression can be presented. The result indicates high correlation between performance and two factors viz. quality and time, although the result is not favourable to support the study hypotheses.

\subsubsection{Factors Analysis}

The factors analysis is conducted to investigate how predictors independently affect each other as well extract the factors, which they are highly correlated together. This test will help indicate which factors are more effectively influence the independent variable as well as affect each other. A Likert Scale is a type of psychometric scale often used in questionnaires related to psychology. It was named and developed after the organizational psychologist Rensis Likert. On a questionnaire or a survey, typically, Likert items are in the format of Strongly disagree, Disagree, Neither agree nor disagree, Agree, and Strongly agree. There is diversity of possible scales of responses (1-3, 1-5, 1-7, and 1-9). All of the mentioned odd-numbered scales possess a middle value and often regarded as Undecided or Neutral. A forced-choice response scale maybe used with responses with an even number and no middle undecided or neutral option. In this case, the responder is obliged to decide whether they svelte more in the direction of the agree or disagree end of each item's scale. A numerical score is assigned for each statement, which is in the range of 1 to 5. A numerical score is given to each level of agreement and the total score of the responders is calculated by means of the scores sum. The respondent's opinion is disclosed by the total score obtained.

Likert Scale is of ordinary type as it enables an individual to rate attitudes, however, it does not analyse the difference between attitudes. The same amount of efforts is required to generate as Thurston scale, which is regarded as more discerning and solid due to the responses' large range specified in Likert scale. The number of statement of a typical scale of Likert scale ranges between 20- 30 statements. To design a good scale of Likert, a large statements pool that are relevant to the attitude measurement ought to be produced and then from statements pool, the ones which are indefinite and non- discerning must be abolished. Therefore, Likert scale is a scale of five-point ranging from "strong agreement" to "strong disagreement". There is involvement of judging gap in this approach.

The studies of correlation are used to examine the occurrence of relationships among variables. There are three possibilities of a correlation study results, which are a negative correlation, a positive correlation and no conclusion. The coefficient of correlation is a quantity that assess the strength of correlation and may fall in the range of (-1 to 1). The table below shows how the factors affect each other either negatively or positively through the application of Eqn 2. In Likert scale, responders are requested to specify the agreement or disagreement amount in form of strong agreement to strong disagreement, using a scale of one- to five-point system. For multiple questions, the same style is applied. This procedure of categorical ranking could be extended to a procedure of evaluation in a straightforward way that applies the numbers full scale instead of verbal categories. Quantitative analysis represented that among the group of five independent variables proposed for this research, correlation exists and should be reconsidered. Two of these variables namely quality and time were accepted as high output of the regression analysis and the regression model for company performance (CP) was presented by Eqn 3.

$$
\begin{gathered}
r_{x y}=\frac{\sum x_{i} y_{i}-n \bar{x} \bar{y}}{(n-1) s_{x} s_{y}}=\frac{n \sum x_{i} y_{i}-\sum x_{i} \sum y_{i}}{\sqrt{n \sum x_{i}^{2}-\left(\sum x_{i}\right)^{2}} \sqrt{n \sum y_{i}^{2}-\left(\sum y_{i}\right)^{2}}} . \\
C P=0.00638+0.246 \text { Quality }+0.226 \text { Time }+0.187 \text { Information }+0.174 \text { Flexibility }+0.167 \text { Integration }
\end{gathered}
$$

Table 2: Ranking of Likert scale

\begin{tabular}{lccccccc}
\hline & $\begin{array}{c}\text { Strongly } \\
\text { Disagree (1) }\end{array}$ & $\begin{array}{c}\text { Disagree } \\
(2)\end{array}$ & Neutral (3) & Agree (4) & $\begin{array}{c}\text { Strongly } \\
\text { Agree (5) }\end{array}$ & Rank & $\begin{array}{c}\text { Percentage } \\
\%\end{array}$ \\
\hline Quality & 2 & 9 & 25 & 102 & 150 & $1^{\text {st }}$ & $25 \%$ \\
Time & 7 & 23 & 28 & 136 & 94 & $2^{\text {nd }}$ & $24 \%$ \\
Information & 19 & 72 & 51 & 90 & 56 & $3^{\text {rd }}$ & $18 \%$ \\
Flexibility & 30 & 90 & 45 & 70 & 53 & $4^{\text {th }}$ & $17 \%$ \\
Integration & 41 & 87 & 44 & 77 & 39 & $5^{\text {th }}$ & $16 \%$ \\
\hline
\end{tabular}


Table 3: Results correlation

\begin{tabular}{|c|c|c|c|c|c|c|}
\hline & SCM & $\begin{array}{c}\text { Qualit } \\
y\end{array}$ & Time & Information & Flexibility & Integration \\
\hline Time & $\begin{array}{c}\text { Pearson correlation } \\
p \text {-Value }\end{array}$ & $\begin{array}{l}-0.051 \\
0.923\end{array}$ & & & & \\
\hline Information & $\begin{array}{c}\text { Pearson correlation } \\
p \text {-Value }\end{array}$ & $\begin{array}{l}0.08 \\
0.88\end{array}$ & $\begin{array}{l}0.545 \\
0.263 \\
\end{array}$ & & & \\
\hline Flexibility & $\begin{array}{c}\text { Pearson correlation } \\
p \text {-Value }\end{array}$ & $\begin{array}{l}-0.135 \\
0.799 \\
\end{array}$ & $\begin{array}{l}0.398 \\
0.434\end{array}$ & $\begin{array}{l}0.237 \\
0.651\end{array}$ & & \\
\hline Integration & $\begin{array}{c}\text { Pearson correlation } \\
p \text {-Value }\end{array}$ & $\begin{array}{l}0.511 \\
0.33 \\
\end{array}$ & $\begin{array}{l}0.261 \\
0.618 \\
\end{array}$ & $\begin{array}{c}0.267 \\
0.6\end{array}$ & $\begin{array}{l}0.311 \\
0.549 \\
\end{array}$ & \\
\hline $\begin{array}{l}\text { Company } \\
\text { performance }\end{array}$ & $\begin{array}{c}\text { Pearson correlation } \\
p \text {-Value }\end{array}$ & $\begin{array}{l}0.494 \\
0.32 \\
\end{array}$ & $\begin{array}{l}0.427 \\
0.398 \\
\end{array}$ & $\begin{array}{l}0.101 \\
0.848 \\
\end{array}$ & $\begin{array}{c}0.0595 \\
0.213 \\
\end{array}$ & $\begin{array}{l}0.09 \\
0.014\end{array}$ \\
\hline
\end{tabular}

There are many coefficients for reliability. Cronbach's alpha is one of the most common coefficients. As Cronbach's alpha could be regarded as coefficient of correlation, it has a range of 0 to 1 while the determined alpha value for the study factors is 0.494 , which is not highly acceptable. Some of the factors would result a slight increase in the Cronbach's alpha, but control the lead-time, quality of production, ability to respond to markets change, and flexibility to change distribution channels.

\subsection{DISCUSSIONS}

This study was directed to determine the significance of some factors in management of supply chain and their influence on the performance of food manufacturing companies. The research considered how the factors such as quality, information, time, flexibility and integration should be managed in the supply chain to ultimately achieve more efficient result in company as well identifying the more important and significant factors to be considered.

Though previous studies indicated that all these factors could more or less influence the performance in an organization, this study indicated the degree of importance of variables as compare to the others. According analysis of regression as well as factor analysis conducted in the previous chapter, quality and time were confirmed to be affecting the food manufacturing companies more effectively. The data analysis demonstrated that managing the quality and time in supply chain is more significant for the companies to accomplish higher performance. By considering the analysis of data that support or contrary to the hypotheses of study, the hypotheses can be divided in two categories:

\section{Accepted Hypotheses:}

H1: The higher the quality in each part of supply chain, the higher the performance of food manufacturing companies $\mathrm{H} 2$ : Time management in supply chain has a positive impact on the performance of food manufacturing companies.

\section{Rejected Hypotheses:}

H3: The better the information among the supply chain; the higher the influence on the performance of the food manufacturing companies.

H4: The company's flexibility to the changes of business environment has a high impact on performance.

$\mathrm{H} 5$ : The integration among supply chain has a great impact on the performance of food manufacturing companies.

\section{SUMMARY}

This research was conducted in order to determine the effect of quality, time, information, flexibility and integration on performance. These factors were chosen by reviewing the previous studies. A questionnaire survey was carried out to investigate the proposition of the research. The data gathered from the survey have been analysed by the SPSS software as well as MINITAB program. In addition, the result of the data collected indicates that two of these variables namely quality and time are affecting the food manufacturing companies' performance according to related hypotheses. Relationships of the independent factors were explained as well as measuring procedures of the most important independent factor were mentioned. Although other variables and the hypotheses were not completely supported by the findings, further studies are essential and different variables can be employed to additional investigate to the food manufacturing companies' performance in supply chain. Rejecting hypotheses illustrate the data that were obtained from the responders are not supportive of the hypotheses. This may be due to following causes:

1. The attained data from respondent are not accurate as not all contributing responders are expert Supply Chain Management.

2. Saudi industries are not enough flexible to the environment changes and adapting to new situations is not taking seriously. 
3. Saudi industries and companies are not as sensitive as the developed countries to the time factor and business in Saudi is running more smoothly and steady.

4. A correlation might occur between the independent variables and they could have a negative impact on each other, therefore, other possible combinations need to be examined.

\subsection{IMPLICATION AND RECOMMENDATION}

This research has been conducted in order to determine the most important factors in supply chain management and then investigate how they supply chain in a company can be modified or refined to improve their efficiency and effectiveness as well as to. The research has illustrated some of the factors affecting the performance. This research examined the relationship between five independent variables and for performance of food manufacturing companies. The result indicated that each variable has its own density of effect on the food manufacturing companies' performance. Further studies are recommended on this topic but considering dissimilar variables as well as different combinations in order to refine the investigation on the factors effecting the performance and efficiency in supply chain namely:

- Investigating the relationship with suppliers and effect of it on organization

- How information technology can contribute in empowering the supply chain and enhancing the performance

- Is it advantageous to be more flexible in organization

- How to improve the deal between the company and suppliers?

\subsection{LIMITATIONS OF THE STUDY}

This research is based on a short and quick survey on SCM to identify the relationship among different variables and performance of food-manufacturing companies. In this research, the following limitations are observed.

- In supply chain, there are several variables affecting the performance; study based on few factors only may not provide the real scenario.

- The demographic data indicates respondents were not all at the managerial level as well as not highly familiar with supply chain management and company structure. Access to desirable number of experts on supply chain management in order to conduct the survey is difficult.

\section{ACKNOWLEDGEMENT}

The authors would like acknowledge the time and effort provided by the respondents. The authors also would like to appreciate very much the support from Department of Manufacturing and Materials Engineering to facilitate data collection and proving the analytical support.

\section{REFERENCES}

1. Hobbs, J. E (1996). A transaction cost approach to supply chain management. Supply Chain Management, 1(2), $15-27$.

2. Kumar, D. \& Rajeev P. V. (2016). Value Chain: A Conceptual Framework. International Journal of Engineering and Management Sciences, 7(1) 74-77.

3. Lhassan, E., Ali, R., \& Majda, F. (2018). Combining SCOR and BPMN to support supply chain decision-making of the pharmaceutical wholesaler-distributors. In Logistics Operations Management (GOL). $4^{\text {th }}$ International Conference on Logistics Operations Management.

4. Neely, A. D., Bourne, M. \& Kennerley, M. (2000). Performance measurement system design: developing and testing a process-based approach. International Journal of Operations \& Production Management, 20(10), 11191145.

5. Zhao, X. et. al. (2002). The impact of information sharing and ordering co-ordination on supply chain performance. Supply Chain Management: An International Journal, 7, 24-40.

6. Najmi, M., Mohamed, H., \& Mukhtar, M. (2018). Performance Measurement of Rice Mills Based on Supply Chain Operation Reference Model. Asia-Pacific Journal of Information Technology and Multimedia, 7(1), 57-69.

7. Savino, M. M., Manzini, R., \& Mazza, A. (2015). Environmental and economic assessment of fresh fruit supply chain through value chain analysis. A case study in chestnuts industry. Production Planning \& Control, 26(1), 118.

8. Expert Choice (2000). Expert Choice Decision Support Software, RWS publications, Pittsburgh, USA.

9. Callado, C., A. A., \& Jack, L. (2015). Balanced scorecard metrics and specific supply chain roles. International Journal of Productivity and Performance Management, 64(2), 288-300.

10. Al-Bawab, A. A. (2017). Use Balanced Scorecard (BSC) Perspectives in the Service Sector: A Case Study on the Jordanian Private Universities. International Business Research, 10(8), 192-203.

11. Brookhart, S. M. \& Durkin, D. T. (2003). Classroom assessment, student motivation, and achievement in high school social studies classes. Applied Measurement In Education, 16(1), 27-54.

12. Kendall, L. (2008). The conduct of qualitative interview: Research questions, methodological issues, and researching online. 
13. Prakash G. (2015). A Framework for Sustainable Food Supply Chain: Reflections from the Indian Dairy Producers. In: Kachitvichyanukul V., Sethanan K., Golinska- Dawson P. (eds) Toward Sustainable Operations of Supply Chain and Logistics Systems. EcoProduction (Environmental Issues in Logistics and Manufacturing). Springer, Cham

14. Suhaiza, Z. \& Premkumar, R. (2005). Supply chain integration and performance: US versus East Asian companies, Supply chain Management: An International Journal, 10(5), 379-393.

15. Tracey, M. \& Lim, J. S. (2005). The impact of supply-chain management capabilities on business performance, Supply chain Management: An International Journal, 10(3), 179-191. 